\title{
Comparison between Intra-Arterial Thrombolysis and Intravenous Thrombolysis in Ischemic Stroke Patients: A Meta-Analysis
}

\author{
Yongkang Liu, Guomin Huang, Zhong Liang Li, Meixiao Zhan, Yong Li, Guangsen \\ Cheng, Ligong Lu* and Yu Liu*
}

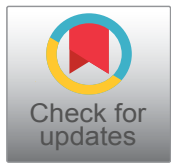

Zhuhai Interventional Medical Center, Zhuhai Precision Medical Center, Zhuhai People's Hospital, Zhuhai Hospital Affiliated with Jinan University, China

*Corresponding author: Yu Liu, Zhuhai Interventional Medical Center, Zhuhai Precision Medical Center, Zhuhai People's Hospital, Zhuhai Hospital Affiliated with Jinan University, Zhuhai, Guangdong, 519000, China;

Ligong Lu, Zhuhai Interventional Medical Center, Zhuhai Precision Medicine Center, Zhuhai People's Hospital, Zhuhai People's Hospital of Jinan University, 79 Kangning Road, Zhuhai, Guangdong 519000, China

\begin{abstract}
Background: To investigate the efficacy and safety between intra-arterial thrombolysis (IAT) and intravenous thrombolysis (IVT) in ischemic stroke patients.

Methods: The full-texts comparing IAT and IVT in ischemic stroke patients were retrieved by PubMed, Embase and Cochrane Central Register of Controlled Trials databases. Review Manager 5.0 was adopted for conducting meta-analysis, sensitivity analysis and bias analysis.

Results: A total of 6 studies including 440 patients with ischemic stroke were included. The results of meta-analysis suggested significant differences between IVT and IAT groups in complete recanalization (relative risk $(R R)=0.58$, 95\% confidence interval $(\mathrm{Cl})[0.48,0.71], P<0.00001 ; P$ for Heterogeneity $=0.70, I^{2}=0 \%$ ). But no significant differences were observed in the National Institutes of Health Stroke Scale (NIHSS) after treatment of symptomatic incidence of intracerebral hemorrhage $(\mathrm{ICH})$ and mortality.

Conclusions: Our study findings suggested that IAT is more efficient than IVT in direct clinical effects in ischemic stroke patients. Analysis of secondary outcome and safety showed no difference. Additional studies with larger sample sizes are strongly needed to further validate our findings.
\end{abstract}

\section{Keywords}

IVT, IAT, Ischemic stroke, Complete recanalization, Meta-analysis

\section{Introduction}

Acute cerebral infarction, commonly referred to as ischemic stroke, is a common disease of the nervous system. It is associated with high disability and mortality rates, causing a serious adverse impact on human health and normal life [1-3]. The prognosis of this disease is closely correlated with prompt and accurate treatment [4-6].

Recombinant tissue plasminogen activator (rt-PA) is the most effective drug for treating ischemic stroke in the ultra-early stage $[7,8]$. Related studies showed that intravenous application of rt-PA within 4.5 hours after the onset of cerebral apoplexy quickly restored cerebral blood perfusion and effectively alleviated the symptoms of hypoxia in ischemic penumbra [7-9]. This in turn greatly reduced the mortality and disability rates in patients with stroke.

It is considered as the most effective treatment for treating acute ischemic stroke by dissolving thrombus, recanalization of occlusive blood vessels and reconstruction of blood flow $[10,11]$. Intravenous thrombolysis (IVT) is simple, but the time window remained short, while intra-arterial thrombolysis (IAT) has a certain degree of trauma in association with complex operation, but the time window is relatively long.

There are several articles that compared the differ-

\footnotetext{
Citation: Liu Y, Huang G, Li ZL, Zhan M, Li Y, et al. (2021) Comparison between Intra-Arterial Thrombolysis and Intravenous Thrombolysis in Ischemic Stroke Patients: A Meta-Analysis. Int J Pediatr Res 7:117. doi.org/10.23937/2469-5807/1510117

Accepted: February 25, 2021: Published: February 27, 2021

Copyright: (c) 2021 Liu Y, et al. This is an open-access article distributed under the terms of the Creative Commons Attribution License, which permits unrestricted use, distribution, and reproduction in any medium, provided the original author and source are credited.
} 
ences between IAT and IVT in patients with ischemic stroke, and there exists various research designs, enrollment and exclusion criteria, methods and so on. Goyal in his study stated that both IAT and IVT have similar effects [7]. While Qureshi reported that IVT was much better than IAT for patients with ischemic stroke [5]. Therefore, meta-analysis was conducted to evaluate IAT and IVT in ischemic stroke patients.

\section{Methods}

\section{Searched databases and strategies}

PubMed, Embase, and Cochrane Central Register of Controlled Trials databases were searched for studies reporting the comparison of IAT and IVT for the treatment of patients with ischemic stroke from January 1 , 2000, to March 16, 2019, were reviewed. The search terms included intravenous thrombolysis or IVT, intra-arterial thrombolysis or IAT and ischemic stroke or IS. Two independent investigators carried out the initial search, deleted duplicate records, screened the titles and abstracts for relevance, and identified the studies that required further assessment. The full-texts of the included articles were reviewed. The references of the retrieved articles and previous reviews were manually checked to identify any additional eligible studies.

\section{Inclusion and exclusion criteria}

Studies were included if:

a) Studies designed as randomized trials or case-control studies.

b) Studies that compared IAT and IVT.

c) Studies involving patients with ischemic stroke diagnosed by radiography.

Studies were excluded if:

a) Case studies/meta-analyses/letter to editors.

b) Studies that did not compare between IAT and IVT.

c) Patients with other diseases.

d) Studies with limited or insufficient data.

e) Duplicate studies.

\section{Data extraction and review}

Eligibility assessment was performed independently in a standardized manner by two reviewers using a predetermined screening form. RCTs in which the patients were diagnosed with ischemic stroke that compared IAT with IVT were included. No restrictions to drug type, dose, mechanical device, or mechanical disruption were imposed. Any disagreements between the reviewers were resolved by reaching consensus.
Two reviewers independently abstracted the data. The data collected from each study included date of publication, first author, nation, number of patients enrolled and randomized in each study, age (years), gender and recruitment period.

A Cochrane risk of bias assessment tool [9] for nonrandomized studies of the effects of interventions was individually applied to all selected studies. The risk of bias in each study was rated as "high risk", "low risk" or "unclear" according to the match level between the information extracted and the evaluation criteria. The authors tried to be fair enough during quality assessment, however, a slight up or down might be possible during grading. This manuscript adhered to the applicable equator guidelines.

\section{Statistical analysis}

Effect sizes for numerical variables were expressed as differences in means with $95 \%$ confidence interval $(\mathrm{Cl})$, while that of categorical data were expressed as relative risk (RR) with $95 \% \mathrm{Cl}$. Heterogeneity between-study was tested with $I^{2}$ measure. Percentages of around $25 \%\left(I^{2}=\right.$ $25), 50 \%\left(I^{2}=50\right)$, and $75 \%\left(I^{2}=75\right)$ were considered as low, moderate, and high heterogeneities, respectively [9].

A $\chi^{2}$ based Q-test was also performed to check between-study heterogeneity. The $I^{2}$ value of higher than 50 indicate moderate heterogeneity between studies, and the effect size for each study was calculated by random effects model DerSimonian-Laird approach. Publication bias was evaluated and quantified by funnel plot, Egger's and Begger's tests. When significant heterogeneity existed across studies, sensitivity analysis was performed by sequential omission of each study to test the influence of each individual study on pooled data. Most of the analyses were performed using Review Manager 5.0 (Cochrane Collaboration, Oxford, United Kingdom) and analysis of publication bias was conducted by STATA 12.0 (StataCorp, College Station, TX).

\section{Results}

\section{Search results}

Electronic search yielded a total number of 805 articles. After thorough reading, 81 studies were considered to meet the preliminary criteria. Further screening excluded 75 articles due to study design, insufficient data and type of the articles. Finally, 6 papers were selected for analysis. Figure 1 presents flowchart of identification, inclusion and exclusion criteria, reflecting the search process and the reasons for exclusion.

\section{Main features of the studies}

Table 1 summarized the type of study reported and the total number of patients associated with each group. The contents included author, publication year, nation, age, gender, group, sample size and recruitment time.

All 6 articles included a total number of 440 patients 


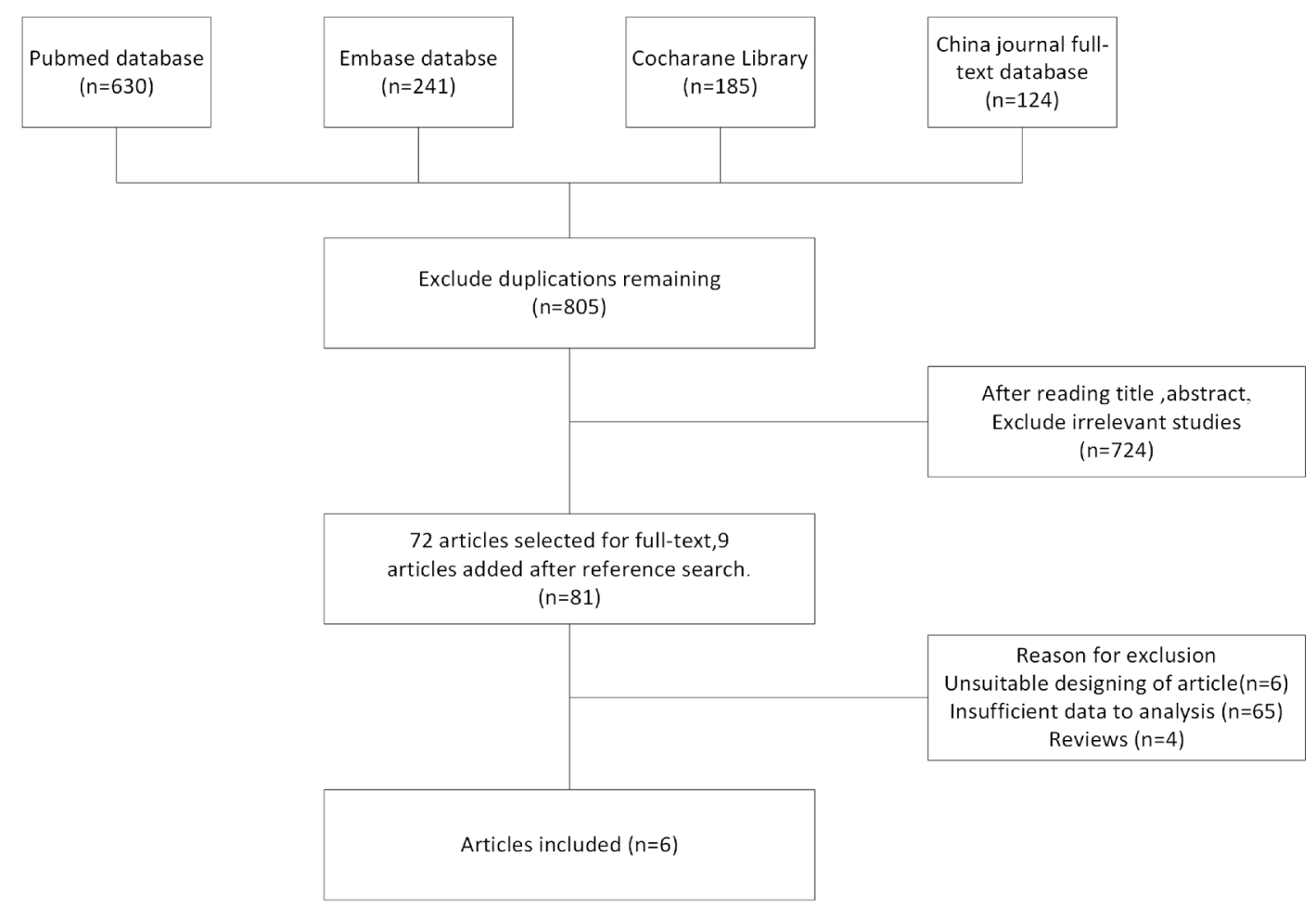

Figure 1: Flow diagram of study identification, inclusion and exclusion.

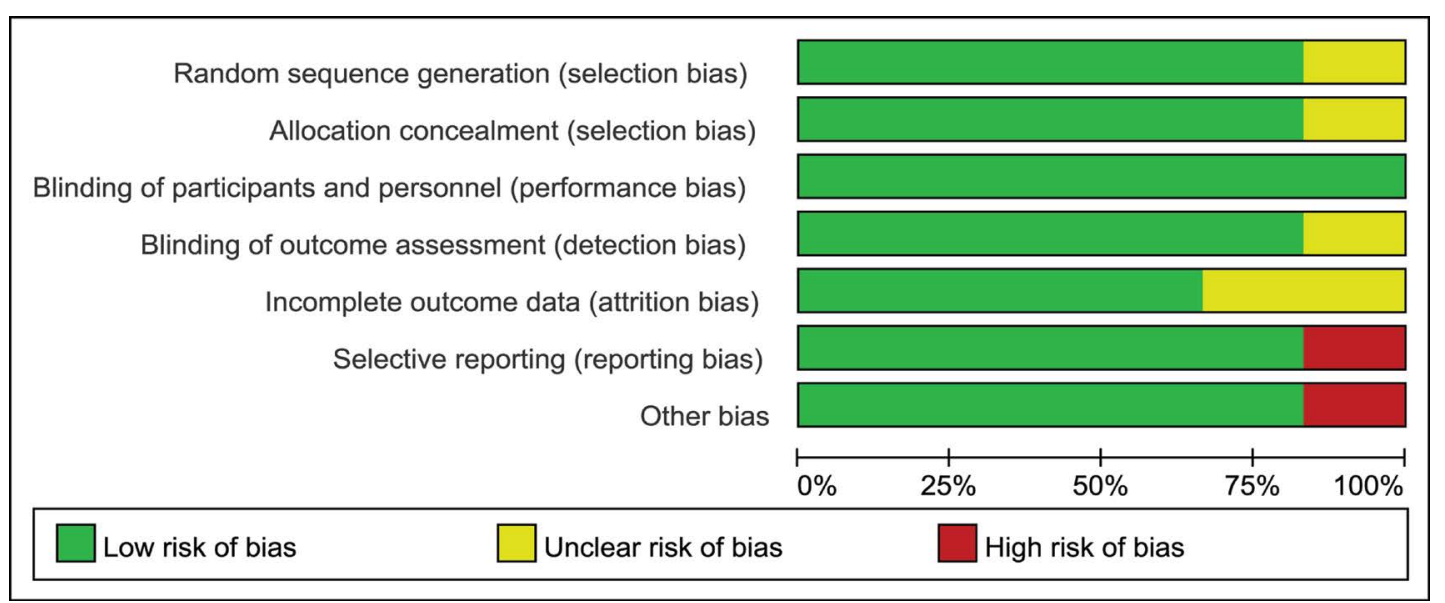

Figure 2: Quality assessment of included studies: Low risk of bias (green hexagons), unclear risk of bias (white hexagons), and high risk of bias (red hexagons).

Table 1: Characteristics of the included studies.

\begin{tabular}{|c|c|c|c|c|c|c|c|}
\hline Study & Year & Nation & Age (years) & Gender (male/female) & Groups & $\mathbf{N}$ & Recruitment time \\
\hline \multirow[t]{2}{*}{ Cabral [25] } & \multirow[t]{2}{*}{2016} & \multirow[t]{2}{*}{ Brazil } & \multirow[t]{2}{*}{ 65.2il NE } & \multirow[t]{2}{*}{$63 / 50$} & IVT & 82 & \multirow[t]{2}{*}{2009 to 2014} \\
\hline & & & & & IAT & 31 & \\
\hline \multirow[t]{2}{*}{ Ciccone [26] } & \multirow[t]{2}{*}{2009} & \multirow[t]{2}{*}{ Italy } & \multirow[t]{2}{*}{ 62.7yN NE } & \multirow[t]{2}{*}{$42 / 12$} & IVT & 29 & \multirow[t]{2}{*}{ January 2004 to February 2008} \\
\hline & & & & & IAT & 25 & \\
\hline \multirow[t]{2}{*}{ Jensen [27] } & \multirow[t]{2}{*}{2016} & \multirow[t]{2}{*}{ USA } & \multirow[t]{2}{*}{ 53.6IN NE } & \multirow[t]{2}{*}{$25 / 10$} & IVT & 11 & \multirow[t]{2}{*}{ January 2010 to May 2015} \\
\hline & & & & & IAT & 24 & \\
\hline \multirow[t]{2}{*}{ Mattle [28] } & \multirow[t]{2}{*}{2007} & \multirow[t]{2}{*}{ Switzerland } & \multirow[t]{2}{*}{ 61.9zerla } & \multirow[t]{2}{*}{$66 / 46$} & IVT & 57 & \multirow[t]{2}{*}{ July 1998 to March 2006} \\
\hline & & & & & IAT & 55 & \\
\hline \multirow[t]{2}{*}{ Sanak [29] } & \multirow[t]{2}{*}{2010} & \multirow[t]{2}{*}{ Czech } & \multirow[t]{2}{*}{$61.5 \mathrm{hN} \mathrm{NE}$} & \multirow[t]{2}{*}{ 19-Nov } & IVT & 20 & \multirow{2}{*}{$\begin{array}{l}\text { January } 2005 \text { to September } \\
2007\end{array}$} \\
\hline & & & & & IAT & 10 & \\
\hline \multirow[t]{2}{*}{ Wolfe [30] } & \multirow[t]{2}{*}{2008} & \multirow[t]{2}{*}{ USA } & \multirow[t]{2}{*}{ 67.5IN NE } & \multirow[t]{2}{*}{$47 / 49$} & IVT & 41 & \multirow[t]{2}{*}{ September 1996 to April 2003} \\
\hline & & & & & IAT & 55 & \\
\hline
\end{tabular}


with 240 in IVT group and 200 in IAT group. The sample size of the included studies ranged between 30 and 113 .

\section{Quality assessment}

The deviation table in the Review Manager 5.0 tutorial was used to assess the risk of each study by applying the criteria for evaluating design-related deviations. The risk of bias in this study was listed in Figure 2. Participants and respondents showed slight bias between IVT group and IAT group. Figure 3 showed detailed information about quality assessment in this article. All 6 studies were associated with low risk.

\section{Results of meta-analysis}

Meta-analysis of complete recanalization: Three studies with 159 patients in IVT group and 96 patients in IAT group underwent complete recanalization. Figure 4 presented heterogeneity analysis of complete recanalization between IVT group and IAT group. All 3 studies showed statistically significant differences in complete recanalization in both IVT and IAT groups. Complete recanalization in IAT was better than that in IVT group (RR $=0.58,95 \% \mathrm{Cl}[0.48,0.71], P<0.00001 ; P$ for Heterogeneity $=0.70, l^{2}=0 \%$ ).

Meta-analysis of NIHSS after treatment: The forest plot for meta-analysis regarding the National Institutes of Health Stroke Scale (NIHSS) after treatment was presented in Figure 5. These results demonstrated that NIHSS after treatment showed no significant difference between IVT $(n=240)$ and IAT $(n=200)$ among ischemic stroke patients $(\mathrm{MD}=-0.89,95 \% \mathrm{Cl}[-2.08,0.30], P=$ 0.14; $P$ for Heterogeneity $\left.=0.17, l^{2}=35 \%\right)$.

Meta-analysis of symptomatic intracerebral hemorrhage (ICH): Meta-analysis about symptomatic ICH was shown in Figure 6. Symptomatic ICH in IVT group (183 samples) showed no difference when compared with

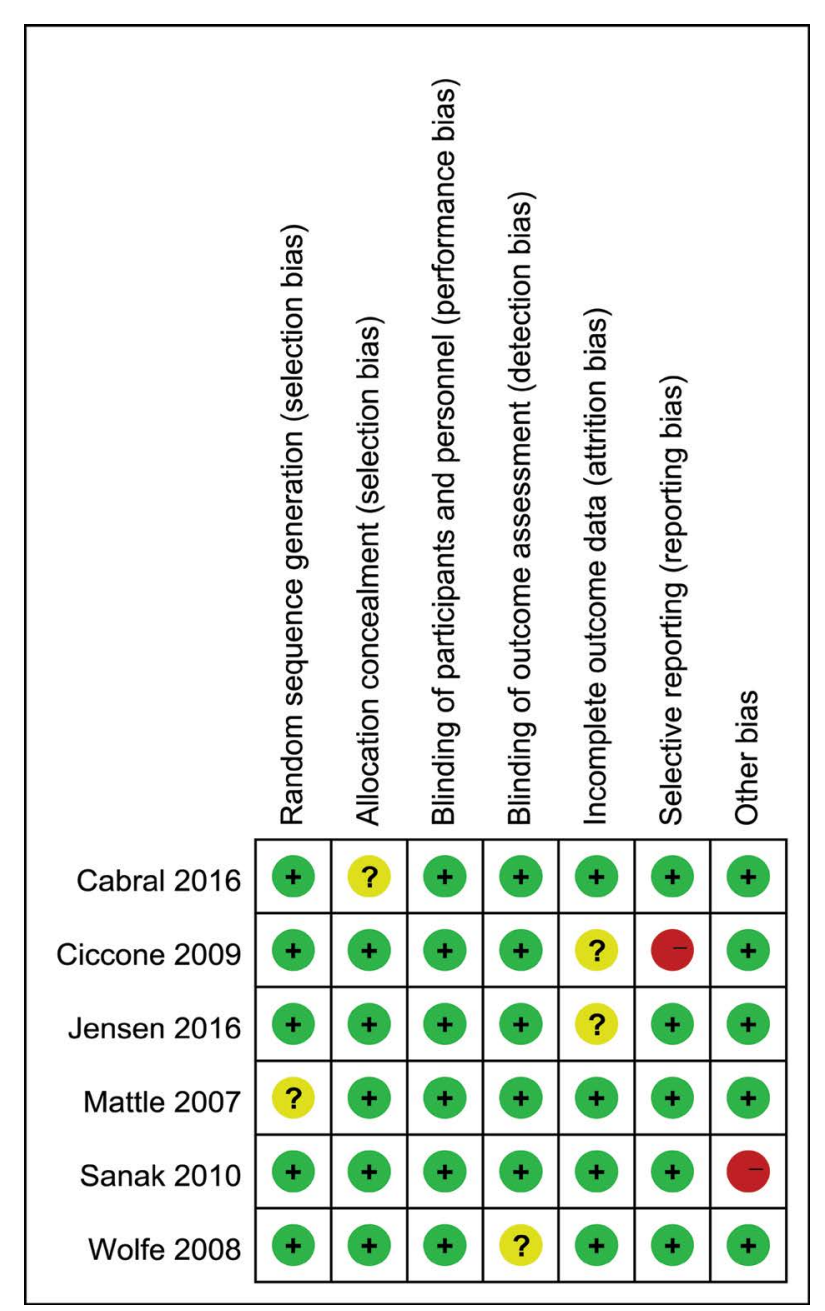

Figure 3: Quality assessment of included studies.

\begin{tabular}{|c|c|c|c|c|c|c|c|c|c|c|}
\hline Study or Subgroup & $\begin{array}{r}\text { IVT } \\
\text { Events }\end{array}$ & Total & $\begin{array}{r}\text { IAT } \\
\text { Events }\end{array}$ & Total & Weight & $\begin{array}{c}\text { Risk Ratio } \\
\text { M-H. Fixed. 95\% Cl }\end{array}$ & \multicolumn{4}{|c|}{$\begin{array}{c}\text { Risk Ratio } \\
\text { M-H. Fixed. } 95 \% \text { CI }\end{array}$} \\
\hline Cabral 2016 & 38 & 82 & 22 & 31 & $34.9 \%$ & $0.65[0.47,0.90]$ & & + & & \\
\hline Mattle 2007 & 27 & 57 & 48 & 55 & $53.4 \%$ & $0.54[0.41,0.73]$ & & 들 & & \\
\hline Sanak 2010 & 9 & 20 & 8 & 10 & $11.7 \%$ & $0.56[0.32,1.00]$ & & 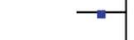 & & \\
\hline Total $(95 \% \mathrm{Cl})$ & & 159 & & 96 & $100.0 \%$ & $0.58[0.48,0.71]$ & & $\checkmark$ & & \\
\hline Total events & 74 & & 78 & & & & & & & \\
\hline $\begin{array}{l}\text { Heterogeneity: } \text { Chi }^{2}= \\
\text { Test for overall effect: }\end{array}$ & $\begin{array}{l}72, \mathrm{df}=2 \\
=5.20(\mathrm{P}\end{array}$ & $\begin{array}{l}2(P=0 \\
<0.0 C\end{array}$ & $\begin{array}{l}.70) ; 1^{2}=( \\
0001)\end{array}$ & & & & 0.01 & $\mathrm{IVT}^{1}$ & IAT & 100 \\
\hline
\end{tabular}

Figure 4: A forest plot for complete recanalization in IVT and IAT groups.

\begin{tabular}{|c|c|c|c|c|c|c|c|c|c|c|c|}
\hline & & IVT & & & IAT & & & Mean Difference & \multirow{2}{*}{\multicolumn{3}{|c|}{$\begin{array}{l}\text { Mean Difference } \\
\text { IV. Fixed. } 95 \% \mathrm{CI}\end{array}$}} \\
\hline Study or Subgroup & Mean & SD & Total & Mean & SD & Total & Weight & IV. Fixed, $95 \% \mathrm{Cl}$ & & & \\
\hline Cabral 2016 & 16 & 6.3 & 82 & 19 & 9.4 & 31 & $11.0 \%$ & $-3.00[-6.58,0.58]$ & & & \\
\hline Ciccone 2009 & 6 & 4.3 & 29 & 9 & 7.3 & 25 & $13.3 \%$ & $-3.00[-6.26,0.26]$ & & & \\
\hline Jensen 2016 & 10 & 5.1 & 11 & 13 & 7.4 & 24 & $7.9 \%$ & $-3.00[-7.22,1.22]$ & & & \\
\hline Mattle 2007 & 17.5 & 4.5 & 57 & 16.7 & 5.1 & 55 & $44.4 \%$ & $0.80[-0.98,2.58]$ & & & \\
\hline Sanak 2010 & 6 & 5.4 & 20 & 9.5 & 13.5 & 10 & $1.9 \%$ & $-3.50[-12.20,5.20]$ & & & \\
\hline Wolfe 2008 & 17 & 5.6 & 41 & 18 & 7.2 & 55 & $21.5 \%$ & $-1.00[-3.56,1.56]$ & & & \\
\hline Total $(95 \% \mathrm{Cl})$ & & & 240 & & & 200 & $100.0 \%$ & $-0.89[-2.08,0.30]$ & & & \\
\hline $\begin{array}{l}\text { Heterogeneity: } \mathrm{Chi}^{2}= \\
\text { Test for overall effect: }\end{array}$ & $\begin{array}{l}.70, \mathrm{df} \\
z=1.47\end{array}$ & $\begin{array}{l}=5(P \\
(P=\end{array}$ & $\begin{array}{l}=0.17 \\
0.14)\end{array}$ & $2^{2}=3$ & $35 \%$ & & & & -10 & ${ }^{-5}$ IVT $^{\text {IAT }}{ }^{5}$ & 10 \\
\hline
\end{tabular}

Figure 5: A forest plot for NIHSS after treatment in IVT group and IAT group. 


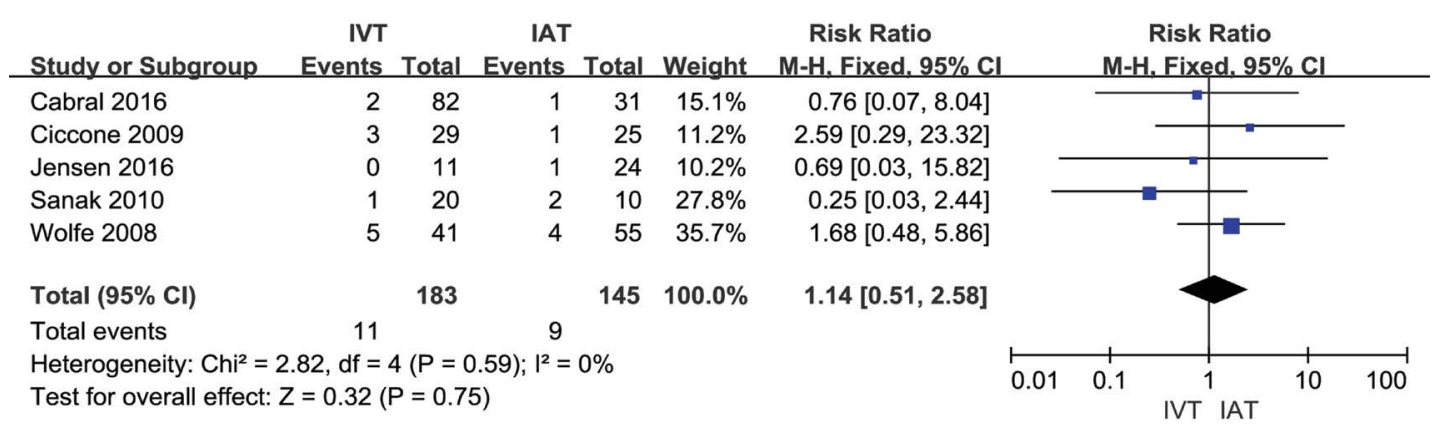

Figure 6: A forest plot for symptomatic ICH in IVT group and IAT group.

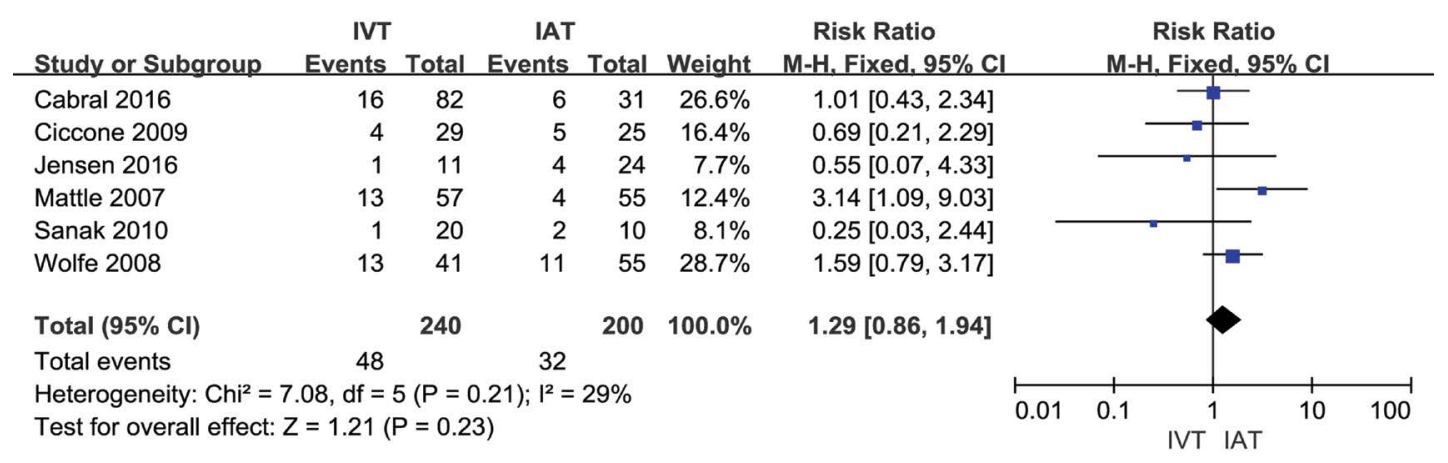

Figure 7: A forest plot for mortality in IVT group and IAT group.

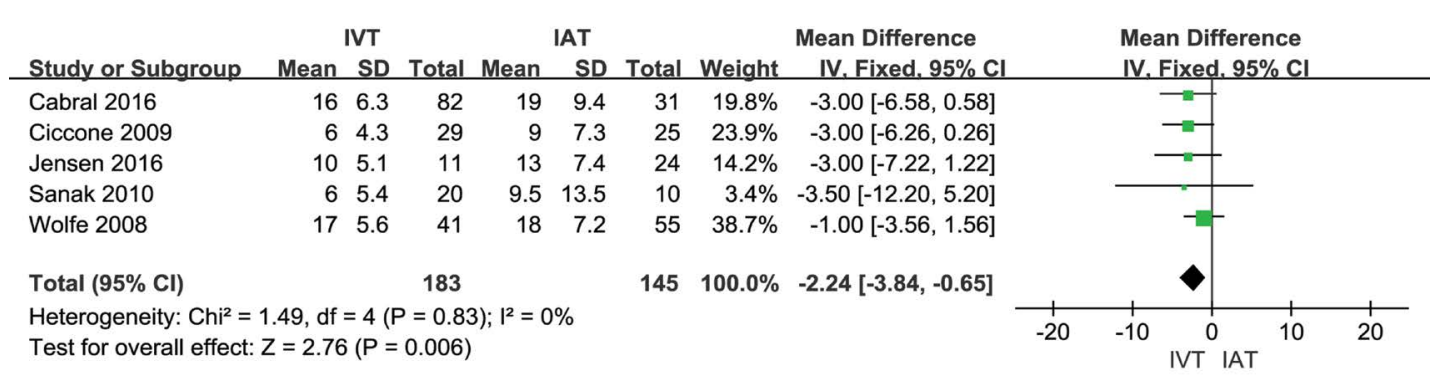

Figure 8: A forest plot for sensitivity analysis in symptomatic ICH among IVT and IAT groups.

IAT group $(\mathrm{n}=145),(\mathrm{RR}=1.14,95 \% \mathrm{Cl}[0.51,2.58], P=$ 0.75; $P$ for Heterogeneity $=0.59, I^{2}=0 \%$ ).

Meta-analysis of mortality: Meta-analysis regarding mortality was shown in Figure 7. The mortality in IVT group ( $\mathrm{n}=240$ ) showed no significant difference when compared with IAT group $(\mathrm{n}=200),(\mathrm{RR}=1.29,95 \% \mathrm{Cl}$ $[0.86,1.94], P=0.23$; $P$ for Heterogeneity $=0.21, l^{2}=29 \%$ ).

\section{Sensitivity analysis}

According to the meta-analysis conducted, heterogeneity of NIHSS was moderate $\left(I^{2}=35 \%\right)$. As shown in Figure 8 , heterogeneity of NIHSS might be attributed to differences in the results of each study. When the article of Mattle in 2007 was excluded, then the $I^{2}$ was changed to $0 \%$ and the mean difference was changed from -0.89 to -2.24 . This indicated that exclusion of this article still showed stable results.

\section{Bias analysis}

Funnel plots of symptomatic ICH in IVT group and IAT group was conducted. All studies are included in the plot. The results showed that the funnel plot had good symmetry and slight publication bias (Figure 9). The results of Begg's and Egger's tests suggested no significant evidence of potential publication bias $(z=1.47, P=$ $0.142)$ and $(\mathrm{t}=1.44, P=0.246)$.

\section{Discussion}

The number of ischemic stroke patients accounted for $60 \%$ to $70 \%$ of the total number of stroke patients [12-14]. Majority of these patients are acute ischemic stroke patients with sudden onset, rapid progression and poor prognosis, and require thrombolytic therapy immediately [15-17].

According to the previous studies, there is a certain relationship between the prognosis of patients with acute ischemic stroke and the recanalization of blood vessels in acute phase. Vascular recanalization in patients with acute ischemic stroke included arterial thrombolysis, arteriovenous thrombolysis, intravenous thrombolysis and mechanical recanalization [18,19]. 


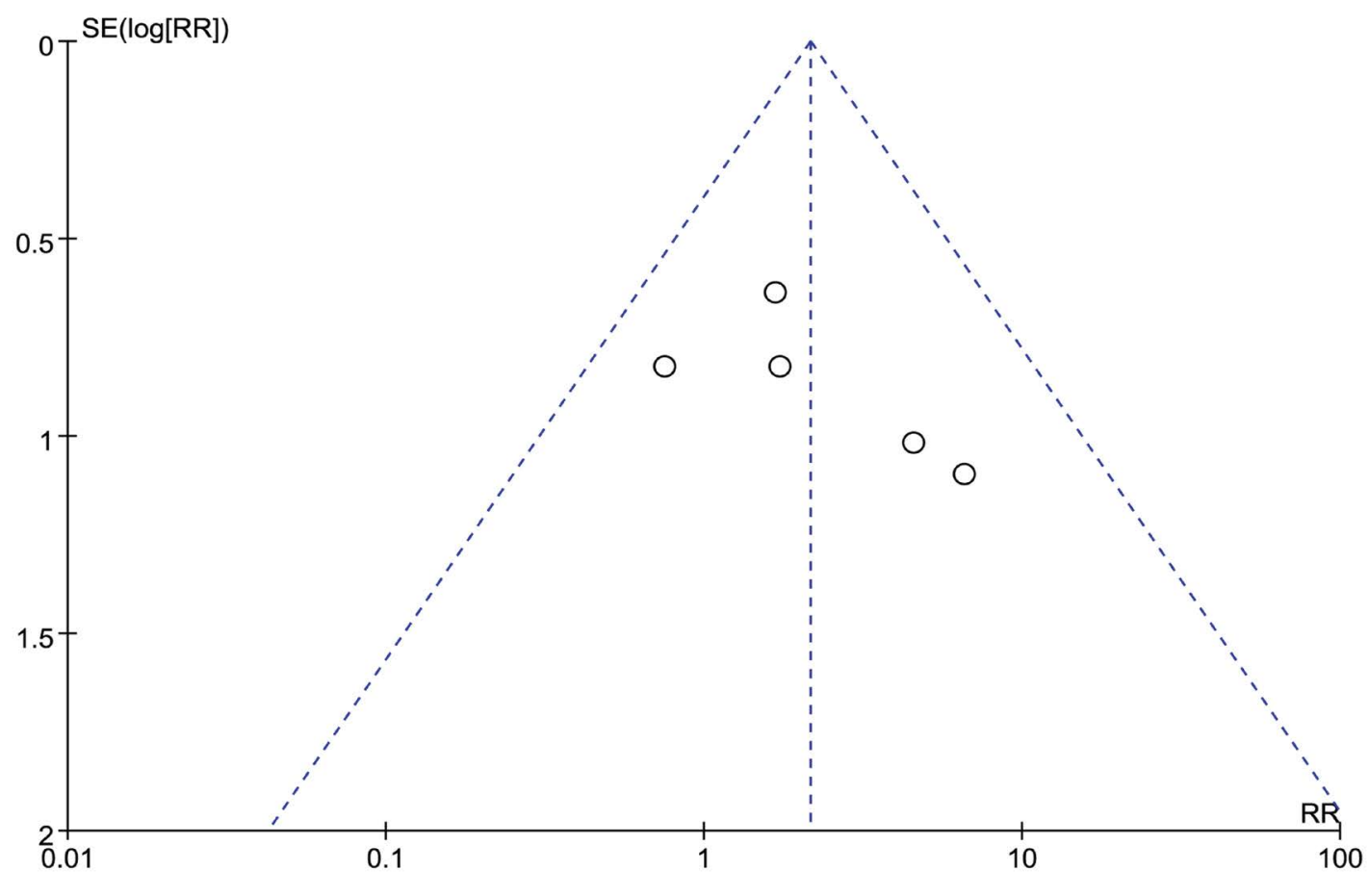

Figure 9: Funnel plot of publication bias.

When considering the efficiency of vascular recanalization, mechanical recanalization demonstrated a higher recanalization rate, but caused more adverse reactions, and the rate of clinical improvement in patients showed no significant improvement. Compared with mechanical recanalization, the recanalization rate of IVT is higher than that of mechanical recanalization. The recanalization rate remained low, but the clinical improvement rate as well as the incidence of non-reaction was lower than that of mechanical recanalization. Arterial thrombolysis demonstrated safety to a certain extent, and involves prolonged treatment period. So, the patients who had lost the opportunity of treatment can be re-treated with thrombolysis $[20,21]$.

The main complications of thrombolytic therapy included $\mathrm{ICH}$, vascular reclusion, ischemia-reperfusion injury and so on. $\mathrm{ICH}$ is the most serious complication in the treatment of acute cerebral apoplexy. However, most of the researchers believed that $\mathrm{ICH}$ is closely related to blood-brain barrier injury, open collateral circulation, wall blood exudation and secondary coagulation dysfunction [22].

In this study, the analysis about complete recanalization showed significant differences. Complete recanalization in IAT group was higher than IVT group, supporting that IAT had better clinical efficacy than IVT. According to Georgiadis, the prognosis of neurological function in patients treated with IAT had better results than those treated with IVT, and this difference might be due to higher recanalization rate of blood vessels after IAT treatment than that after IVT treatment [23].

In the secondary outcome of NIHSS, symptomatic ICH and mortality, IVT group showed no significant difference from that of IAT group. These results were consistent with the research conducted by Arnold [24]. This might because thrombolytic drugs can selectively bind to fibrin on the surface of the thrombus, and have strong specificity and affinity. No matter what the method is used in the time window, a safe thrombolytic effect can be obtained.

However, some limitations still existed in this study. Firstly, heterogeneities among studies were observed. According to the funnel plots, limited publication bias still existed. The heterogeneities were mainly attributed due to the different therapies in patients with ischemic stroke. Secondly, more studies in different countries could be analyzed. Thirdly, larger sample studies could be included. Further investigation should be conducted with the above discussed limitations in future.

In conclusion, the present study demonstrated that complete recanalization in IAT was better than that in IVT group. But no significant difference was observed in NIHSS after treatment, symptomatic ICH and mortality rates. Our results suggested that IAT may have better clinical effects than IVT, while IAT and IVT demonstrated similar secondary outcomes and safety effects. However, our findings should be carefully considered with caution due to small sample size. Additional studies with large study population are essential to further confirm our findings in future.

\section{Acknowledgments}

None.

\section{Author Contributions Statement}

YL conceived and coordinated the study, designed, performed and analyzed the experiments, wrote the pa- 
per. YKL, ZLLi, MXZ, YLi, WYZ, GSC, ZHL, GJT, LGL carried out the data collection, data analysis, and revised the paper. All authors reviewed the results and approved the final version of the manuscript.

\section{Conflict of Interest Statement}

The authors declare that they have no conflict of interests.

\section{Funding}

This work was supported by National Key Research and Development Program of China (No.2017YFA0205200), National Natural Science Foundation of China (No.81571785, 81771957), Natural Science Foundation of Guangdong Province, China (No.2016A030311055, 2016A030313770, 2018A030313074), and China Postdoctoral Science Foundation (2018M631038).

\section{Contribution to the Field Statement}

There are several articles that compared the differences between IAT and IVT in patients with ischemic stroke, and there exists various research designs, enrollment and exclusion criteria, methods and so on. Some studies stated that both IAT and IVT have similar effects. While some other reported that IVT was much better than IAT for patients with ischemic stroke. The comparison between IAT and IVT was still controversial. Therefore, meta-analysis was conducted to evaluate IAT and IVT in ischemic stroke patients. This article is a supplement and update to analysis the efficiency and safety between IAT and IVT for patients with ischemic stroke.

\section{References}

1. Abbondanzi F, Biscaro G, Carvalho G, Favaro L, Lemos $P$, et al. (2017) Fast method for the determination of shortchain-length polyhydroxyalkanoates (scl-PHAs) in bacterial samples by In Vial-Thermolysis (IVT). N Biotechnol 39: 2935.

2. Mardis C, Bal T, Levy R (2007) The masks of allergy undone by IVT. MLO Med Lab Obs 39: 14-19.

3. Holman TJ, Wilson MH, Kenobi K, Dryden IL, Hodgman TC, et al. (2010) Statistical evaluation of transcriptomic data generated using the Affymetrix one-cycle, two-cycle and IVT-Express RNA labelling protocols with the Arabidopsis ATH1 microarray. Plant Methods 6: 9.

4. Ciccone A, Valvassori L, Gasparotti R, Scomazzoni F, Ballabio E (2007) Debunking 7 myths that hamper the realization of randomized controlled trials on intra-arterial thrombolysis for acute ischemic stroke. Stroke 38: 2191-2195.

5. Qureshi Al, Suri MF, Nasar A, He W, Kirmani JF, et al. (2005) Thrombolysis for ischemic stroke in the United States: Data from National Hospital Discharge Survey 1999-2001. Neurosurgery 57: 647-654.

6. Siegler JE, Galetta S (2018) Editors' note: Comparative safety and efficacy of combined IVT and MT with direct MT in large vessel occlusion. Neurology 91: 1114.

7. Goyal N, Tsivgoulis G, Alexandrov AV, Arthur AS (2018) Author response: Comparative safety and efficacy of combined IVT and MT with direct MT in large vessel occlusion. Neurology 91: 1116.
8. Lahens NF, Kavakli IH, Zhang R, Hayer K, Black MB, et al. (2014) IVT-seq reveals extreme bias in RNA sequencing. Genome Biol 15: R86.

9. Johler SM, Rejman J, Guan S, Rosenecker J (2015) Nebulisation of IVT mRNA complexes for intrapulmonary administration. PLoS One 10: e0137504.

10. Grier AE, Burleigh S, Sahni J, Clough CA, Cardot V, et al. (2016) pEVL: A Linear plasmid for generating mRNA IVT templates with extended encoded poly $(A)$ sequences. Mol Ther Nucleic Acids 5: e306.

11. Lopez-Espejo M, Hernandez-Chavez M, Huete I (2019) Risk factors for in-hospital and follow-up mortality after childhood arterial ischemic stroke. J Neurol 266: 15261532.

12. Giudice C, Rogers EE, Johnson BC, Glass HC, Shapiro KA (2018) Neuroanatomical correlates of sensory deficits in children with neonatal arterial ischemic stroke. Dev Med Child Neurol 61: 667-671.

13. Goldenberg NA, Jenkins S, Jack J, Armstrong-Wells J, Fenton LZ, et al. (2013) Arteriopathy, D-dimer, and risk of poor neurologic outcome in childhood-onset arterial ischemic stroke. J Pediatr 162: 1041.

14. Liu AJ, Zang P, Guo JM, Wang W, Dong WZ, et al. (2012) Involvement of acetylcholine-alpha7nAChR in the protective effects of arterial baroreflex against ischemic stroke. CNS Neurosci Ther 18: 918-926.

15. Yang F, Yue H, Wu L, Qin X, Shi L, et al. (2017) Ischemic stroke due to intracranial arterial dolichoectasia coexisting with spontaneous dissection of the basilar artery: A case report. Medicine (Baltimore) 96: e8422.

16. Sveinsson O, Herrman L, Holmin S (2016) Intra-arterial mechanical thrombectomy: An effective treatment for ischemic stroke caused by endocarditis. Case Rep Neurol 8: 229-233.

17. Mair G, von Kummer R, Lindley RI, Sandercock PA, Wardlaw JM (2015) Effect of X-ray attenuation of arterial obstructions on intravenous thrombolysis and outcome after ischemic stroke. PLoS One 10: e0145683.

18. Mackay MT, Monagle P, Babl FE (2017) Improving diagnosis of childhood arterial ischaemic stroke. Expert Rev Neurother 17: 1157-1165.

19. Chaudhuri JR, Kumar R, Umamahesh M, Mridula KR, Alladi S, et al. (2016) Outcome of acute ischemic stroke after intra-arterial thrombolysis: A study from India. Iran J Neurol 15: 195-201.

20. Mehta BK, Kamal H, McMurtray A, Shafie M, Li P (2015) Effect of heparin on recanalization in acute stroke patients with intra-arterial thrombi. Neurol Int 7: 5807.

21. Hills NK, Johnston SC, Sidney S, Zielinski BA, Fullerton HJ (2012) Recent trauma and acute infection as risk factors for childhood arterial ischemic stroke. Ann Neurol 72: 850-858.

22. Barbosa Junior AA, Ellovitch SRdS, Pincerato RdCM (2012) Imaging findings and cerebral perfusion in arterial ischemic stroke due to transient cerebral arteriopathy in children. Einstein 10: 239-241.

23. Georgiadis $D$, Engelter $S$, Tettenborn $B$, Hungerbuhler $H$, Luethy $R$, et al. (2006) Early recurrent ischemic stroke in stroke patients undergoing intravenous thrombolysis. Circulation 114: 237-241.

24. Opie LH, White D, Lee J, Lubbe WF (2012) Alternatives to beta-blockade in therapy of hypertension with angina pectoris: Role of nifedipine or of labetalol. $\mathrm{Br} \mathrm{J}$ Clin Pharmacol 13: $115 \mathrm{~S}-122 \mathrm{~S}$. 
25. Cabral NL, Conforto A, Magalhaes PSC, Longo AL, Moro $\mathrm{CHC}$, et al. (2016) Intravenous rtPA versus mechanical thrombectomy in acute ischemic stroke: A historical cohort in Joinville, Brazil. eNeurologicalSci 5: 1-6.

26. Ciccone A, Valvassori L, Ponzio M, Ballabio E, Gasparotti $R$, et al. (2010) Intra-arterial or intravenous thrombolysis for acute ischemic stroke? The SYNTHESIS pilot trial. J Neurointerv Surg 2: 74-79.

27. Jensen J, Salottolo K, Frei D, Loy D, McCarthy K, et al. (2017) Comprehensive analysis of intra-arterial treatment for acute ischemic stroke due to cervical artery dissection. J Neurointerv Surg 9: 654-658.
28. Mattle HP, Arnold M, Georgiadis D, Baumann C, Nedeltchev $\mathrm{K}$, et al. (2008) Comparison of intraarterial and intravenous thrombolysis for ischemic stroke with hyperdense middle cerebral artery sign. Stroke 39: 379-383.

29. Sanak D, Herzig R, Skoloudik D, Horak D, Zapletalova J, et al. (2010) The safety and efficacy of continuous transcranial duplex Doppler monitoring of middle cerebral artery occlusion in acute stroke patients: Comparison of TCDD and thrombolysis in MCA recanalization. J Neuroimaging 20: $58-63$.

30. Wolfe T, Suarez JI, Tarr RW, Welter E, Landis D, et al. (2008) Comparison of combined venous and arterial thrombolysis with primary arterial therapy using recombinant tissue plasminogen activator in acute ischemic stroke. $\mathrm{J}$ Stroke Cerebrovasc Dis 17: 121-128. 